\title{
Rekayasa Tata Letak Mesin CNC Laser Trumpf L3030 dan Fasilitas Produksi di PT. X
}

\author{
Rosyita Firdaus, Departemen Teknik Desain dan Manufaktur, Politeknik Perkapalan Negeri \\ Surabaya, Anda Iviana Juniani, Teknik Desain dan Manufaktur, Politeknik Perkapalan Negeri \\ Surabaya, dan Farizi Rachman, Teknik Desain dan Manufaktur, Politeknik Perkapalan Negeri \\ Surabaya
}

\begin{abstract}
Abstrak - Penelitian ini bertujan untuk merancang layout PT. X untuk meminimalkan jarak tempuh material handling. Perusahaan membuka plant baru dengan memindahkan mesin lama pada pabrik baru serta mendatangkan mesin baru (L3030). Dengan demikian, pengaturan penempatan mesin dan perencanaan layout harus direncanakan dengan hati-hati karena perusahaan menggunakan sistem jobshop sehingga waktu dapat digunakan secara maksimal untuk proses pemesinan. Solusi untuk perusahaan adalah rekayasa tata letak mesin CNC Laser Trumpf L3030 dan penataan fasilitas produksi menggunakan metode Systematic Layout Planning (SLP). Prosedur re-layout terdiri dari tiga langkah: menganalisis tata letak awal, merancang alternatif tata letak berdasarkan SLP, mengevaluasi dan memilih tata letak alternatif dengan teknik perbandingan biaya. Peningkatan efisiensi material handling dan pengurangan moving distance diperoleh dari alternatif Layout 1. Hasil yang diperoleh menunjukkan penurunan moving distance hingga $28,5 \%$, dan pengurangan total biaya material handling hingga $18.4 \%$ dari tata letak awal.
\end{abstract}

Kata Kunci-Systematic Layout Planning, Layout, Material Handling.

\section{Pendahuluan}

$\mathrm{P}$ T. X adalah perusahaan yang bergerak di bidang fabrikasi sheet metal dengan menggunakan sistem produksi jobshop. Saat ini, perusahaan mulai melakukan perluasan area produksi dengan membuka plant 2. Dengan area plant 2 untuk proses sederhana dan area plant 1 untuk proses yang lebih kompleks. Oleh karena itu pemindahan mesin sesuai kebutuhan proses akan dilakukan. Beberapa mesin dari plant 1 akan dipindahkan ke plant 2, dan pada plant 1 akan didatangkan beberapa mesin baru.

Selain keadaan tersebut, terdapat beberapa masalah pada proses produksi. Pertama, yaitu banyaknya pekerjaan yang harus dilakukan oleh operator sehingga mengharuskan operator bergerak cepat untuk memaksimalkan waktu pada proses machining. Yang harus dikerjakan oleh operator tersebut antara lain; mengoperasikan mesin, mengambil raw

Rosyita Firdaus, Departemen Teknik Desain dan Manufaktur, Politeknik Perkapalan Negeri Surabaya, Surabaya, Jawa Timur, Indonesia

Anda Iviana Juniani, Teknik Desain dan Manufaktur, Politeknik Perkapalan Negeri Surabaya, Surabaya, Jawa Timur, Indonesia

Farizi Rachman, Teknik Desain dan Manufaktur, Politeknik Perkapalan Negeri Surabaya, Surabaya, Jawa Timur, Indonesia material, mengantarkan produk setengah jadi ke proses selanjutnya, serta melakukan quality control terhadap barang yang sudah jadi. Kedua, luas area WIP yang tersedia belum mencukupi sehingga ketika terdapat penumpukan bahan baku maupun produk setengah jadi menyebabkan ruang gerak forklift menyempit. Selain itu, pada area produksi akan ditambahkan satu mesin CNC Laser Trumpf L3030.

Penyelesaian masalah yang digunakan untuk perbaikan di PT. X yaitu rekayasa tata letak mesin CNC Laser Trumpf L3030 dan fasilitas produksi dengan menggunakan metode Systematic Layout Planning (SLP). Metode SLP memberikan proses secara bertahap mulai dari mengidentifikasi aliran material, menentukan hubungan antar divisi, menentukan bagaimana pemanfaatan ruang, mempertimbangkan batasan yang ada, diharapkan akan didapatkan perancangan layout yang efektif dapat mengurangi biaya operasional hingga 10-30\% [1]. Alternatif layout hasil dari metode SLP lebih teratur bentuknya sehingga lebih diminati dan mudah untuk diterapkan seperti penelitian sebelumya dengan judul Design and Simulation Plant Layout Using Systematic Layuot Planning PT. Gunaprima Budiwijaya dengan permasalahan yang dihadapi berupa cross traffic pada lantai produksi. Penelitian tersebut menunjukkan peningkatan hasil kapasitas produksi sebesar $37.5 \%$ dan mengurangi ongkos material handling sebesar $10,98 \%$ [2]

Tujuan dari penelitian ini yaitu untuk merancang sebuah desain tata letak baru yang lebih efisien dan memberikan ruang gerak yang luas serta meningkatkan efisiensi material handling dan meminimalkan ongkos material handling. Dengan harapan perusahaan dapat mengaplikasikan hasil desain tata letak baru ini dan tercapainya tujuan yang tersebut. Dalam penelitian ini fokus membahas perancangan fasilitas produksi pada divisi produksi plant $1 \mathrm{PT}$. X, tidak melakukan perubahan sistem produksi maupun urutan produksi yang telah ada, serta membahas produk dengan urutan proses sampai finishing karena jumlah pesanan banyak dan waktu pemrosesan lama.

\section{Metodologi}

\section{A. Pengumpulan Data}

Produk yang akan diteliti pada penelitian ini merupakan 
produk yang memiliki kuantitas yang terbilang tinggi, sering diproduksi, serta memiliki alur proses produksi yang panjang. Tiap jenis produk memiliki volume produksi berdasarkan permintaan dari customer selama tiga bulan terakhir sebagai berikut:

TABEL I

JENIS DAN JUMLAH PRODUK

\begin{tabular}{clcc}
\hline \hline No. & \multirow{2}{*}{ Jenis Pesanan } & Jumlah & Satuan \\
\hline 1 & Panel Server & 15 & Unit \\
2 & Box Print & 90 & Unit \\
3 & Kiosk & 33 & Unit \\
\hline \hline
\end{tabular}

Penggambaran layout awal yang ada dapat di lihat pada Gambar 1 berikut ini:

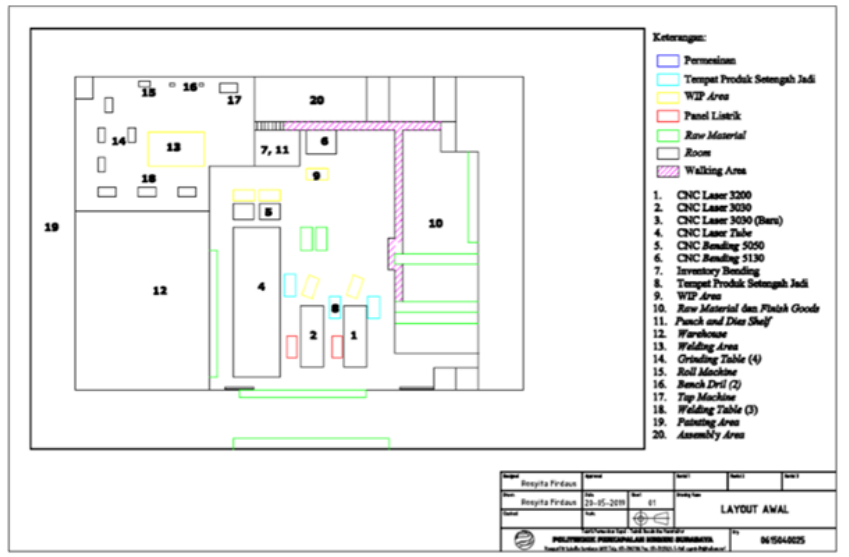

Gambar. 1. Layout Awal

\section{B. Pengolahan Data}

Hal pertama yang arus dilakukan yaitu routing untuk menentukan urutan operasi setiap proses dan waktu pengerjaan tiap proses sehingga data tersebut bisa memberikan gambaran berapa lama produk dapat dikerjaan dengan urutan proses yang ada. Kemudian pembuatan flow process chart untuk menggambarkan peta aliran proses baik yang bersifat produktif (operasi dan inspeksi) ataupun tidak produktif (transportasi, menunggu, dan menyimpan) dari awal sampai akhir kegiatan akan diuraikan secara detail [3].

Tipe layout yang digunakan di PT. X yaitu Process layout. Dalam layout ini mesin dan peralatan yang mempunyai fungsi sama dikelompokkan menjadi satu departemen agar lebih fleksibel. Bentuk pola aliran yang akan digunakan dalam penelitian ini berupa combination layout seperti $U$-shape dan Circular. U-shape digunakan agar akhir dari proses produksi berada pada lokasi yang sama dengan awal prosess produksi. Circular digunakan untuk mengembalikan material atau produk pada titik awal aliran produksi berlangsung, selalin itu pola ini bisa dipakai apabila departemen peneriman dan pengiriman berada pada lokasi yang sama [3].

Proses selanjutnya yaitu pembuatan Activity Relationship Chart (ARC) berdasarkan kedekatan hubungan fasilitas atau departemen satu dengan lainnya seperti pada Gambar 2 berikut ini:

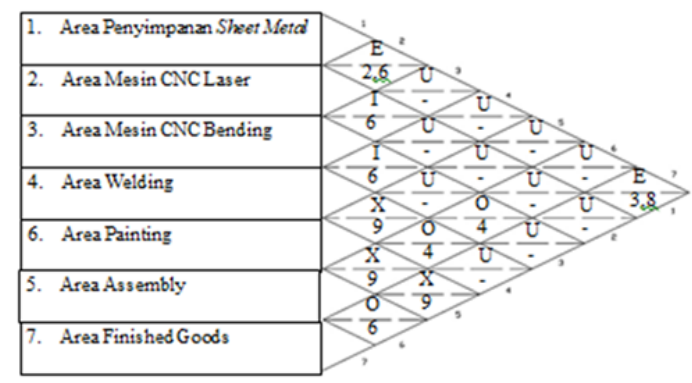

Gambar. 2. Peta Keterkaitan Panel Server, Box Print, dan Kiosk

Kemudian dilakukan pembuatan Activity Relationship Diagram (ARD) menjelaskan mengenai pola aliran bahan dan lokasi dari masing-masing departemen penunjang terhadap departemen produksiya dengan memakai kombinasi garis (dan juga warna) sebagai standar penggambaran derajat hubungan aktivitas seperti pada Gambar 3 dan Gambar 4 berikut ini:

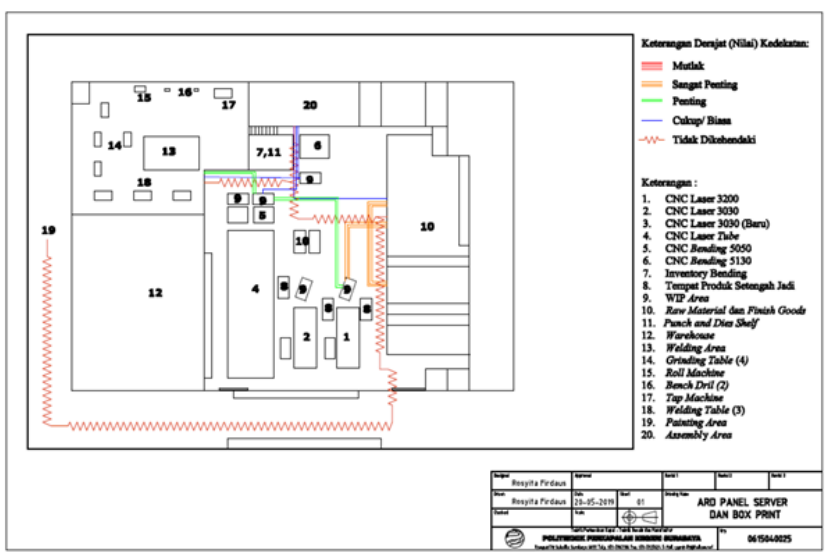

Gambar. 3. ARD Panel Server, Box Print

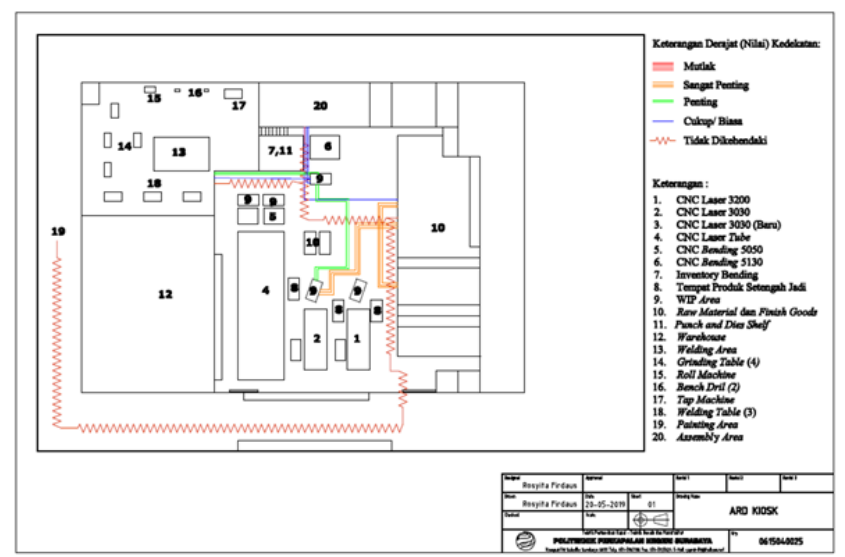

Gambar. 4. ARD Kiosk

Setelah itu dilanjutkan dengan perhitungan space requirement untuk kebutuhan fasilitas berdasarkan spesifikasi teknis dari mesin baru yang akan didatangkan maupun fasilitas produksi yang telah ada. Untuk setiap mesin atau fasilitas pendukung digunakan toleransi $0,75-1$ meter pada setiap sisi mesin dan untuk kelonggaran operator (allowance) sebesar 50\% [4]. 


\section{Perancangan Layout}

Setelah melalui proses diatas dilanjutkan dengan perhitungan jarak dengan metode Euclidean dengan rumus sebagai berikut:

$$
(A-B)=\sqrt{\left[(x i-x j)^{2}+(y i-y j)^{2}\right]}
$$

Perhitungan waktu yang diperlukan untuk menempuh jarak yang ada dilakukan dengan mencatat waktu perpindahan dengan stopwatch dengan metode Time Study Analist. Sedangkan waktu rata-rata setelah pengambilan sampel waktu digunakan metode standart time dengan allowance yang ditetapkan oleh perusahaan sebesar 5\% dari jam kerja efektif selama 8 jam dengan rumus sebagai berikut [6]:

Standard Time $=$ Normal Time $\times \frac{100 \%}{100 \%-\% \text { Allowance }}$

Langkah selanjutnya yaitu menghitung total cost dan $\mathrm{OMH} / \mathrm{m}$ dengan rumus sebagai berikut [5]:

$O M H / m=\frac{\text { cost }}{\mathrm{d}}$

Sehingga didapatkan Total OMH dengan d mewakili jarak dan $\mathrm{f}$ adalah frekuensi material handling, sehingga didapatkan rumus sebagai berikut [5]:

Total $O M H=f \times d \times O M H / m$

\section{HASIL DAN PEMBAHASAN}

Berdasarkan pengolahan data tersebut maka dapat diketahui data layout awal dan hasil perancangan 3 alternatif layout. Kemudian dibandingkan antara layout awal dengan 3 alternatif layout yang meliputi jarak material handing dan ongkos material handling. Perbandingan tersebut dapat dilihat pada Tabel 2 dan Tabel 3 berikut ini:

TABEL II

PERBANDINGAN JARAK MENGGUNAKAN FORKLIFT

\begin{tabular}{|c|c|c|c|c|}
\hline \multirow{2}{*}{$\begin{array}{c}\text { Jenis } \\
\text { Produk }\end{array}$} & \multicolumn{4}{|c|}{ Total Jarak Perpindahan (m) } \\
\hline & $\begin{array}{l}\text { Layout } \\
\text { Awal }\end{array}$ & Alternatif 1 & Alternatif 2 & Alternatif 3 \\
\hline $\begin{array}{l}\text { Panel } \\
\text { Server }\end{array}$ & $1.100,21$ & 882,79 & 989,22 & 957,75 \\
\hline $\begin{array}{l}\text { Box } \\
\text { Print }\end{array}$ & $1.268,45$ & 777,51 & 886,42 & 800,89 \\
\hline Kiosk & 581,05 & 448,83 & 451,11 & 474,68 \\
\hline Total & $2.949,71$ & $2.109,13$ & 2326,75 & 2.233 .32 \\
\hline \multicolumn{5}{|c|}{$\begin{array}{r}\text { TABEL III } \\
\text { PERBANDINGAN TOTAL BIAYA PERPINL }\end{array}$} \\
\hline \multirow{2}{*}{$\begin{array}{c}\text { Jenis } \\
\text { Produk }\end{array}$} & \multicolumn{4}{|c|}{ Total Biaya Perpindahan Material (Rp) } \\
\hline & $\begin{array}{l}\text { Layout } \\
\text { Awal }\end{array}$ & Alternatif 1 & Alternatif 2 & Alternatif 3 \\
\hline Forklift & 965.104 & 683.451 & 746.307 & 726.937 \\
\hline $\begin{array}{l}\text { Vacuum } \\
\text { Lifter }\end{array}$ & 570.189 & 570.273 & 517.060 & 534.166 \\
\hline Total & 1.535 .293 & 1.253 .724 & 1.263 .447 & 1.261 .103 \\
\hline
\end{tabular}

Dari table diatas didapatkan didapatkan layout biaya terendah dari layout 1 sebesar $\mathrm{Rp}$ 1.253.724 dan dari segi jarak didapatkan layout 1 dengan jarak terpendek sebesar 2.109,13 m. Maka dipilihlah layout 1 untuk dijadikan layout usulan. Sehingga perbandingan jarak antara layout lama dan layout baru dapat disimpulkan pada Gambar 5 berikut ini:

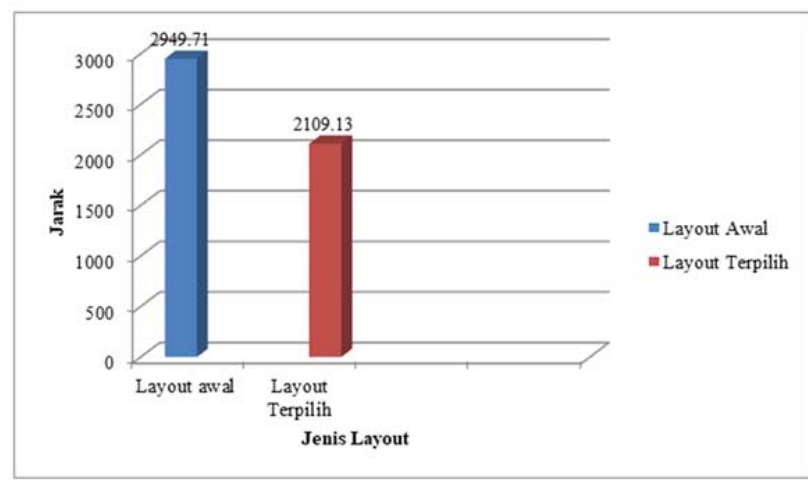

Gambar. 5. Grafik Perbandingan Total Jarak

$$
\begin{aligned}
\text { Correction Jarak } & =\frac{2.949,71-2.109,13}{2.949,71} \times 100 \% \\
& =28.5 \%
\end{aligned}
$$

Grafik diatas menunjukkan perbandingan total jarak layout awal sebesar $2.949,71 \mathrm{~m}$ sedangkan total jarak layout terpilih mengalami penurunan menjadi $2.109,13 \mathrm{~m}$. Maka didapatkan efisiensi jarak tempuh material handling dengan menggunakan jarak Euclidean sebesar 28.5\%. Sedangkan grafik perbandingan $\mathrm{OMH}$ layout awal dan baru dengan forklift dapat disimpulkan pada Gambar 6 berikut ini:

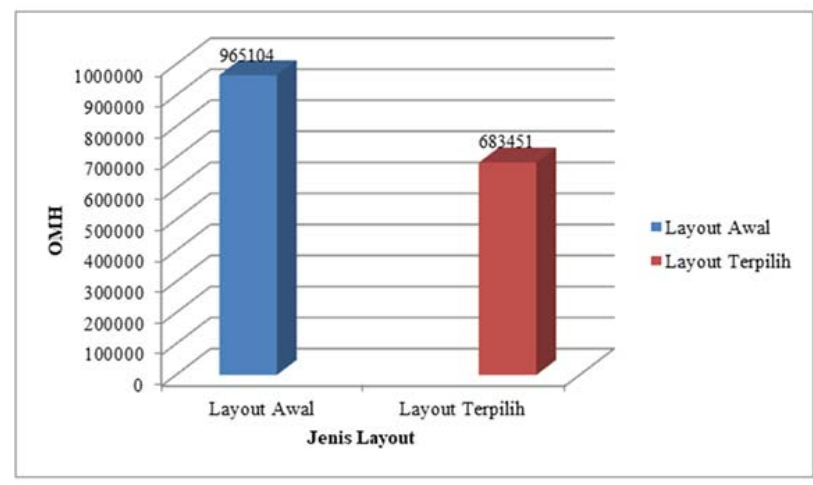

Gambar. 6. Grafik Perbandingan OMH Forklift

$$
\begin{aligned}
\text { Correction OMH Forklift } & =\frac{965.104-683.451}{965.104} \times 100 \% \\
& =29.18 \%
\end{aligned}
$$

Grafik diatas menunjukkan OMH layout awal sebesar Rp 965.104 sedangkan OMH layout terpilih mengalami penurunan menjadi Rp 683.451. Maka didapatkan efisiensi ongkos material handling menggunakan forklift sebesar $29.18 \%$. Sedangkan grafik perbandingan Total OMH layout awal dan layout terpilih dijelaskan pada Gambar 7 berikut ini: 


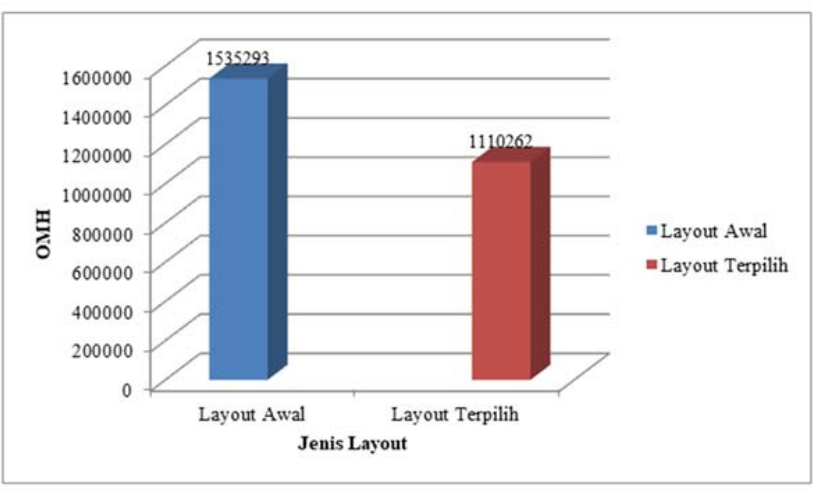

Gambar. 7. Grafik Perbandingan Total OMH

$$
\begin{aligned}
\text { Correction Total OMH } & =\frac{1.535 .293-1.253 .724}{1.535 .293} \times 100 \% \\
& =18.4 \%
\end{aligned}
$$

Grafik diatas menunjukkan perbandingan Total OMH layout awal sebesar Rp 1.535.293,-- sedangkan Total OMH layout terpilih mengalami penurunan menjadi Rp 1.253.724. Maka didapatkan efisiensi total ongkos material handling sebesar $18.4 \%$.

Berikut adalah layout usulan yang didapat dari perhitungan dan efisiensi yang telah ditambahkan dengan penempatan mesin baru yaitu CNC Laser Trumpf L3030.

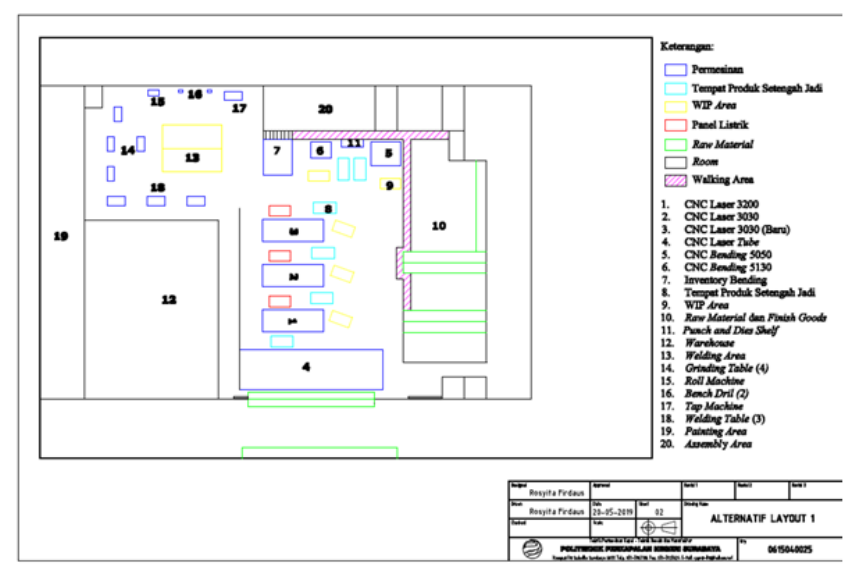

Gambar. 8. Layout Usulan

\section{KESIMPULAN}

Kesimpulan yang dapat diambil dari perancangan layout baru dengan mempertimbangkan peletakan mesin CNC Laser Trumpf L3030 dan perbaikan tata letak fasilitas produksi di departemen produksi PT. X Laser Metalindo adalah sebagai berikut:

1) Peletakan mesin CNC Laser Trumpf L3030 dikelompokkan berdasarkan jenis mesinnya, sehingga mesin baru tersebut diletakkan pada area mesin laser yang letaknya dekat dengan area raw material berdasarkan pada urutan aliran proses produksinya. Perbaikan penataan fasilitas produksi dilakukan dengan re-design layout lama dengan menggunakan metode Systematic Layout Planning (SLP) dengan mempertimbangkan peletakan mesin baru. Proedur re-design terdiri dari tiga step yaitu : analisa layout awal, membuat desain layout alternatif berdasarkan SLP, evaluasi dan pemilihan alternatif layout dengan menggunakan cost comparison technique.

2) Hasil analisa layout terpilih didapatkan jarak tempuh material handling sebesar 2.949,71m menjadi 2.109,13 m. Hasil terebut didapatkan dari perhitungan jarak Euclidean dan meningkatkan efisiensi material handling sebesar 28.5\%. Perbandingan Total OMH layout awal sebesar Rp1.535.293/hari menjadi Rp 1.253.724/hari, sehingga dapat menghasilkan efisiensi total ongkos material handling sebesar $18.4 \%$ per hari.

\section{UCAPAN TERIMA KASIH / ACKNOLEDGMENT}

Penulisan Jurnal ini tidak lepas dari bantuan berbagai pihak, oleh karena itu penulis ingin menyampaikan terima kasih sebesar-besarnya kepada:

1) Orang tua penulis (Tarsono dan Sumaiyah), adik penulis (Rosyela Firdaus) dan seluruh keluarga yang senantiasa memberi bantuan, dukungan, perhatian, nasihat dan saran.

2) Ibu Anda Iviana Juniani, ST., MT selaku Ketua Program Studi Teknik Desain dan Manufaktur Dosen Pembimbing I yang telah berkenan meluangkan waktu untuk memberikan bimbingan, saran dan ilmu kepada penulis dalam menyelesaikan Jurnal Tugas Akhir ini.

3) Bapak Farizi Rachman, S.Si. M.Si. selaku Dosen Pembimbing II dan Koordinator Tugas Akhir Program Studi Teknik Desain dan Manufaktur yang telah berkenan meluangkan waktu untuk memberikan bimbingan, saran dan ilmu kepada penulis dalam menyelesaikan Jurnal ini.

\section{DAFTAR PUSTAKA}

[1] Barwal, S. and Darmadhikari, P. (2016). Optimization of Plant Layout Using SLP Method. IOP Conference Series: Engineering and Technology, 5 (3): p.1-8.

[2] Suhardini, D., Septiani, W., \& Fauziah, S. (2017). Plant Layout Design and Simulation Using Systematic Layout Planning. IOP Conference Series: Materials Science and Engineering, 277 (1): p.18.

[3] Wignjosoebroto, S. (2003). Plant Layout and Material Moving. Surabaya: Guna Widya.

[4] Purnomo, H. (2004). Planning and Design Facility. Yogyakarta: Graha Science.

[5] Nasution, H., Budiman, I., \& Salim, A. (2018). The Cost Analysis of Material Handling in Chinese Traditional Praying Paper Production Plant. IOP Conference Series: Materials Science and Engineering, 309(1): p.1-8.

[6] Tarigan, U., \& Sukirman. (2019). Integration of Lean Manufacturing and Group Technology Layout to increase production speed in the Manufacture of Furniture Integration. IOP Conference Series: Materials Science and Engineering, 309(1). : p.1-8. 